\title{
Distal arthrogryposis type 5D
}

INSERM

\section{Source}

INSERM. (1999). Orphanet: an online rare disease and orphan drug data base. Distal arthrogryposis type 5D. ORPHA:329457

Distal arthrogryposis type 5D is a rare subtype of distal arthrog ryposis syndrome characterized by arthrogryposis multiplex cong enita affecting the hands, feet, ankle, shoulders and/or neck, with camptodactyly of the fingers and limited knee and hip extension, associated with asymmetric ptosis and, less frequently, other ocular manifestations (e.g. ophthalmoplegia, strabismus). Affected individuals frequently have a bulbous nose, furrowed tongue, micro/retrognathia, a short neck, congenital hip dislocation, club feet, scoliosis and short stature. 